\title{
Chapter 10 \\ New Options for Investigating Macro-level \\ Variation in Segregation
}

The previous chapter established that the difference of means framework for measuring segregation makes it possible to investigate segregation in a single city using individual-level models of residential attainment. The discussion in this chapter reviews how this approach can be extended to investigate ecological (i.e., aggregatelevel) variation in segregation across cities and over time using multi-level models of individual residential attainments. The key is that ecological variation in segregation can be investigated by assessing how the effect of race on segregation-relevant individual residential outcomes is conditioned by time and/or city characteristics. A central advantage of this approach is that it permits researchers to also include relevant non-racial social and economic characteristics in the micro-model. This allows effects of community characteristics to be estimated at the "zero order" level or "net" of controls for non-racial factors. It also can help overcome the risk of errors of inference that are likely to occur in aggregate-level analyses that attempt to control for relevant individual-level social and economic characteristics using aggregate-level indicators of group disparity on these variables.

\subsection{New Specifications for Conducting Comparative and/or Trend Analyses of Segregation}

Investigations of how segregation varies across metropolitan areas and over time are a staple of segregation studies. The new methods outlined here can be used to first exactly replicate earlier studies and then to extend them in new ways. Results from previous studies can be exactly replicated by estimating contextual and multi-level models where variation in segregation over time and across metropolitan areas is captured by assessing how the effect of race in individual-level models of residential attainment varies with time and/or the ecological characteristics of metropolitan areas. For example, consider the question of how White-Black segregation 
measured by the index of dissimilarity (D) varies across cities based on city size (lnpop=the natural logarithm of total population) and relative minority size ( $\mathrm{rpb}=$ the square root of proportion Black for the city population).

Following the typical aggregate-level approach, cities are taken as units of analysis, D is calculated separately for individual cities, and scores for D then are taken as dependent variables (y) in a city-level OLS regression analysis that includes city size (lnpop) and relative minority size (rpb) as predictors as follows.

$$
\mathrm{y}_{\mathrm{i}}=a_{0}+a_{1}(\operatorname{lnpop})+a_{2}(\mathrm{rpb})
$$

I estimated this equation using city-level data for the 201 metropolitan areas that had 50,000 total households and 2000 Black households in the 2000 Census. ${ }^{1}$ I obtained the following results.

$$
\mathrm{y}_{\mathrm{i}}=55.92+3.90(\operatorname{lnpop})+4.79(\mathrm{rpb})
$$

These effect values also can be obtained from an individual-level, contextual model that takes as its dependent variable the individual-level residential outcome (y) relevant for D - that is, whether the (pairwise) proportion White (p) for the area in which the individual resides is equal to or greater than the city-wide figure $(\mathrm{P})$ and then also includes as a predictor the individual characteristic of race (coded 1 if White and 0 if Black) and appropriate interactions to capture how the effect of race on residential outcomes varies by city size (lnpop) and relative minority size (rpb). The result is the following individual-level OLS regression specification.

$$
\mathrm{y}_{\mathrm{i}}=b_{0}+b_{1}(\text { race })+b_{2}(\operatorname{lnpop})+b_{3}(\mathrm{rpb})+b_{4}(\text { race } \cdot \operatorname{lnpop})+b_{5}(\text { race } \cdot \mathrm{rpb})
$$

I estimated this equation using individual-level-level data for the White and Black households in the same set of 201 metropolitan areas used in the aggregate analysis just reported above and I obtained the following results. ${ }^{2}$

$$
\begin{aligned}
\mathrm{y}_{\mathrm{i}}= & 17.58+55.92(\text { race })+-1.671(\operatorname{lnpop})+12.75(\mathrm{rpb}) \\
& +3.90(\text { race } \cdot \operatorname{lnpop})+4.79(\text { race } \cdot \mathrm{rpb})
\end{aligned}
$$

\footnotetext{
${ }^{1}$ The data for the analyses are obtained from the tabulation of household income by race for census block groups in Tables 15.1 (A-I) distributed in Summary File 3 of the 2000 Census.

${ }^{2}$ One must give attention to how cases are weighted to replicate the unstandardized regression coefficients from the city-level regression. The city-level regression implicitly gives equal weight to each group's mean for the relevant residential outcomes (y) in every city. To implement the same weighting scheme at the individual level, I first calculated each household's proportionate share of the race-specific group total for the city in which it resided. I then multiplied these share values by 2000 , the minimum number of households for any group in any city, and used the resulting number as the case weight for the household. One may consider other weighting approaches at the individual level. But something along the lines of the approach just noted is required to exactly reproduce the city-level regression coefficients.
} 
The results document that the additive and non-additive effects of race in the individuallevel contextual regression correspond exactly to the coefficients in the city-level regression. Specifically, $\mathrm{b}_{1}=\mathrm{a}_{0}=55.92, \mathrm{~b}_{4}=\mathrm{a}_{1}=3.90$, and $\mathrm{b}_{5}=\mathrm{a}_{2}=4.79$.

I present the city-level and household-level regressions in Table 10.1. The table also includes regressions for the additive components that define D; namely, the percentages of Whites living in areas where proportion White exceeds the city proportion and the comparable percentage of Blacks. Inspection of the results shows that the effects of city size (lnpop) and relative minority size (rpb) on D can be traced to the differential effects these city characteristics have on the levels of residential contact White and Black households have with Whites.

The table also provides a parallel analysis for the separation index (S). As seen for the analysis for $\mathrm{D}$, coefficients in the city-level regression for $\mathrm{S}$ map exactly onto coefficients in the individual-level contextual regression and the separate regressions and the results for $\mathrm{S}$ can be traced to the differential effects city characteristics have on the residential contact Whites and Blacks have with Whites.

I next extended the analysis to do something that previously has not been possible - namely, to investigate variation in segregation across cities and/or over time while simultaneously taking account of non-racial characteristics of households at the micro-level. This is possible because the summary file tabulations - namely, Table 151 (A-I) from Summary File 3 of the 2000 Census - provide the individual level data needed to perform this analysis. To accomplish the task, I re-estimated the contextual regressions reported in Table 10.1 after adding household income and the interaction of race and household income as predictors in the analysis. The results are presented in Table 10.2.

The impact of race on White-Black differences in residential outcomes and how these differences vary with city characteristics are registered in the same way as before. But here the segregation effects - that is the effect of race on residential outcomes - can be interpreted as being estimated net of the effects of that income has on residential outcomes. In the model specification used here, higher income is seen to lead to greater contact with Whites, a finding consistent with results reported in the literature on residential attainment. But note that the introduction of the control for income at the individual level has little impact on the effects of city size and relative minority size on segregation. That is, the impacts of city size and relative minority size on the coefficient for race in this analysis closely parallel the same effects observed for these variables in the city-level and individual-level contextual regressions that do not include individual income as a control variable.

I do not present city-level regressions in Table 10.2 because aggregate specifications cannot properly take account of the role of group differences in socioeconomic characteristics. I have outlined the general basis for this conclusion in an earlier paper focusing on the logically similar task of assessing the role of group differences in education in city variation in racial income inequality (Fossett 1988). The conclusions of that methodological study apply with full force to the present situation. That is, to correctly assess how group differences in socioeconomic attainments impact city variation in segregation, one must draw on data that disaggregates 
Table 10.1 Regression results illustrating that effects in city-level analyses of segregation and contact can be obtained using individual-level, contextual regressions predicting group differences in contact

\begin{tabular}{lccc}
\hline City-level regressions for dissimilarity index (D) & $\mathrm{D}$ & $\begin{array}{c}\mathrm{D} \text { contact } \\
\mathrm{P}_{\mathrm{W}(\mathrm{p} \geq \mathrm{P})}\end{array}$ & $\begin{array}{l}\text { D contact } \\
\mathrm{P}_{\mathrm{B}(\mathrm{p} \geq \mathrm{P})}\end{array}$ \\
\hline \multicolumn{2}{l}{ City-level effects on segregation (group contact difference) and group contact terms } \\
$\quad$ City size (lnpop) $\left(a_{1}, b_{4}\right)$ & $3.90^{\mathrm{a}}$ & $2.23^{\mathrm{a}}$ & $-1.67^{\mathrm{a}}$ \\
Relative minority size $(\mathrm{rpb})\left(a_{2}, b_{5}\right)$ & 4.79 & $17.54^{\mathrm{a}}$ & $12.75^{\mathrm{a}}$ \\
City-level intercept $\left(a_{0}, b_{1}\right)$ & $55.92^{\mathrm{a}}$ & $73.50^{\mathrm{a}}$ & $17.58^{\mathrm{a}}$ \\
Sample N & 201 & 201 & 201 \\
Individual-Level, Contextual Regressions for & y for D & y for D & y for D \\
Dissimilarity Index (D) & Pooled & Whites & Blacks
\end{tabular}

City-level effects on segregation (group contact difference) and group contact terms ${ }^{\mathrm{d}}$

$\begin{array}{lrrr}\text { City size (lnpop) }\left(a_{1}, b_{4}\right) & 3.90^{\mathrm{a}} & 2.23^{\mathrm{a}} & -1.67^{\mathrm{a}} \\ \text { Relative minority size }(\mathrm{rpb})\left(a_{2}, b_{5}\right) & 4.79^{\mathrm{a}} & 17.54^{\mathrm{a}} & 12.75^{\mathrm{a}} \\ \text { City-level intercept }\left(a_{0}, b_{1}\right) & 55.92^{\mathrm{a}} & 73.50^{\mathrm{a}} & 17.58^{\mathrm{a}}\end{array}$

Additional individual-level effects

City size (main effect lnpop, $b_{2}$ ) $\quad-1.67^{\mathrm{a}}$

Relative minority size (main effect rpb, $b_{3}$ ) $\quad 12.75^{\mathrm{a}}$

Individual-level intercept $\left(b_{0}\right)$

$17.58^{\mathrm{a}}$

Sample N

$804,000^{c}$

$402,000^{\mathrm{c}}$

$402,000^{c}$

\begin{tabular}{llll}
\hline City-level regressions for separation index (S) & $\mathrm{S}$ & $\begin{array}{l}\text { S Contact } \\
\mathrm{P}^{*}{ }_{\mathrm{ww}}\end{array}$ & $\begin{array}{l}\text { S Contact } \\
\mathrm{P}^{*}{ }_{\mathrm{BW}}\end{array}$ \\
\hline
\end{tabular}

City-level effects on segregation (group contact difference) and group contact terms ${ }^{\mathrm{d}}$
City size (lnpop) $\left(a_{1}, b_{4}\right)$
$5.83^{\mathrm{a}}$
$0.59^{\mathrm{b}}$
$-5.24^{\mathrm{a}}$
Relative minority size (rpb) $\left(a_{2}, b_{5}\right)$
$70.51^{\mathrm{a}}$
$-35.39^{\mathrm{a}}$
$-105.90^{\mathrm{a}}$
City-level intercept $\left(a_{0}, b_{l}\right)$
$11.76^{\mathrm{a}}$
$99.78^{\mathrm{a}}$
$88.02^{\mathrm{a}}$
201
201
201
Individual-level, contextual regressions for separation index (S)
y for $S$
y for $S$
y for $S$

Pooled Whites Blacks

Sample N

City-level effects on segregation (group contact difference) and group contact terms ${ }^{\mathrm{d}}$
City size (lnpop) $\left(a_{1}, b_{4}\right)$
$5.83^{\mathrm{a}}$
$0.59^{\mathrm{a}}$
$-5.24^{\mathrm{a}}$
Relative minority size (rpb) $\left(a_{2}, b_{5}\right)$
$70.51^{\mathrm{a}}$
$-35.39^{\mathrm{a}}$
$-105.90^{\mathrm{a}}$
City-level intercept $\left(a_{0}, b_{1}\right)$
$11.76^{\mathrm{a}}$
$99.78^{\mathrm{a}}$
$88.02^{\mathrm{a}}$

Additional individual-level effects

City size (main effect lnpop, $b_{2}$ )

Relative minority size (main effect rpb, $b_{3}$ )

$-105.90^{\mathrm{a}}$

Individual-level intercept $\left(b_{0}\right)$

$88.02^{\mathrm{a}}$

Sample N

$804,000^{\circ}$

$402,000^{c}$

(continued) 
Table 10.1 (continued)

Source: Summary File 3, Census 2000

${ }^{\mathrm{a}} \mathrm{p}<0.001$

${ }^{\mathrm{b}} \mathrm{p}<0.01$

${ }^{\mathrm{c}}$ Weighting of cases is described in the text

${ }^{\mathrm{d}} \mathrm{In}$ the city-level regressions for $\mathrm{D}$ and $\mathrm{S}$, the equation is $\mathrm{y}=a_{0}+a_{1}(\operatorname{lnpop})+a_{2}(\mathrm{rpb})$ and the citylevel effects are $a_{0}, a_{1}$, and $a_{2}$. In the individual-level, contextual regressions y is scaled pairwise contact based on $\mathrm{y}=\mathrm{f}(\mathrm{p})$ as appropriate for $\mathrm{D}$ and $\mathrm{S}$. The equation is $\mathrm{y}=b_{0}+b_{1}($ race $)+b_{2}(\operatorname{lnpop})$ $+b_{3}(\mathrm{rpb})+b_{4}$ (race-Inpop) $+b_{5}\left(\right.$ race-rpb). City-level effects are captured by coefficients $b_{1}=a_{0}$, $b_{4}=a_{1}$, and $b_{5}=a_{2}$. The variables lnpop and rbp are centered on values at the observed sample minimum, lnpop on 12.0 , and $\mathrm{rbp}$ on 0.10 , to make the regression intercepts substantively meaningful

residential outcomes by race and socioeconomic status as is the case for the individual-level contextual regressions in Table 10.2.

Due to the lack of viable alternative methods, past studies sometimes have instead adopted the approach of including aggregate (i.e., city-level) measures of group differences in socioeconomic status as control variables in analyses predicting segregation (e.g., Marshall and Jiobu 1975; Roof et al. 1976; Farley and Frey 1994; Massey and Denton 1987). Unfortunately, this approach is flawed. As noted earlier, it can yield misleading results because it runs afoul of the "aggregate" or "ecological" fallacy in using aggregate-level measures to take account of the role of variables whose impact should properly be assessed at the micro level. I do not provide an extended discussion of the general issues to since I have reviewed them in an earlier study (Fossett 1988). But I do highlight the practical significance of the problem by reporting analyses in Table 10.3 that replicate central findings reported in Fossett (1988) using an empirical example investigating cross-city variation in segregation. The first column in Table 10.3 reports results of conventional city-level regressions that predict $\mathrm{D}$ and $\mathrm{S}$ using city characteristics. The second column reports results of regressions that add a city-level measure of Black-White income inequality as a predictor. Many aggregate analyses of segregation have used similar model specifications motivated by the plausible conjecture that segregation between groups will be larger when their disparity on income is larger.

The results of the aggregate regression suggest that group income differences have dramatic impacts on segregation. But this finding is contradicted by the results of the contextual analyses reported in Table 10.2. It also is at odds results from the cityspecific standardization exercises for Houston, Texas reported earlier in Table 9.4. These analyses controlled for socioeconomic characteristics at the individual level and the results indicated that socioeconomic characteristics were not generally important in shaping racial segregation. Specifically, these analyses indicated that 
Table 10.2 Analyses illustrating how city-level analyses of segregation can be conducted using individual-level, contextual regressions that control non-racial characteristics

\begin{tabular}{lcc}
\hline Regressions for Dissimilarity Index $(\mathrm{D})$ & y for D & y for D \\
\hline City size (Inpop) $\left(a_{1}, b_{4}\right)$ & $3.90^{\mathrm{a}}$ & $3.97^{\mathrm{a}}$ \\
Relative minority size $(\mathrm{rpb})\left(a_{2}, b_{5}\right)$ & $4.79^{\mathrm{a}}$ & $2.24^{\mathrm{a}}$ \\
City-level intercept $\left(a_{0}, b_{1}\right)$ & $55.92^{\mathrm{a}}$ & $56.35^{\mathrm{a}}$ \\
Additional individual-level effects & & \\
City size (main effect lnpop, $\left.b_{2}\right)$ & $-1.67^{\mathrm{a}}$ & $-2.39^{\mathrm{a}}$ \\
Relative minority size (main effect rpb, $\left.b_{3}\right)$ & $12.75^{\mathrm{a}}$ & $15.62^{\mathrm{a}}$ \\
Income $\left(b_{6}\right)$ & - & $3.36^{\mathrm{a}}$ \\
Race-income interaction $\left(b_{7}\right)$ & - & $-1.16^{\mathrm{a}}$ \\
Individual-level intercept $\left(b_{0}\right)$ & $17.58^{\mathrm{a}}$ & $11.40^{\mathrm{a}}$ \\
\hline Regressions for Separation Index $(\mathrm{S})$ & $\mathrm{y} \mathrm{for} \mathrm{S}$ & y for S \\
\hline Implied city-level effects on segregation \& contact & & $6.26^{\mathrm{a}}$ \\
City size (lnpop) $\left(a_{1}, b_{4}\right)$ & $5.83^{\mathrm{a}}$ & $68.05^{\mathrm{a}}$ \\
Relative minority size (rpb) $\left(a_{2}, b_{5}\right)$ & $70.51^{\mathrm{a}}$ & $15.40^{\mathrm{a}}$ \\
City-level intercept $\left(a_{0}, b_{1}\right)$ & $11.76^{\mathrm{a}}$ & \\
Additional individual-level effects & & $-5.88^{\mathrm{a}}$ \\
City size (main effect lnpop, $\left.b_{2}\right)$ & $-5.24^{\mathrm{a}}$ & $-103.33^{\mathrm{a}}$ \\
Relative minority size $\left(\right.$ main effect rpb, $\left.b_{3}\right)$ & $-105.90^{\mathrm{a}}$ & $3.00^{\mathrm{a}}$ \\
Income $\left(b_{6}\right)$ & - & $-2.28^{\mathrm{a}}$ \\
Race-income interaction $\left(b_{7}\right)$ & - & $82.51^{\mathrm{a}}$ \\
Individual-level intercept $\left(b_{0}\right)$ & $88.02^{\mathrm{a}}$ & $804,000^{\mathrm{b}}$ \\
Sample N & $804,000^{\mathrm{b}}$ &
\end{tabular}

Source: Summary File 3, Census 2000

${ }^{\mathrm{a}} \mathrm{p}<0.001$

${ }^{\mathrm{b}}$ Weighting of cases is described in the text

'In individual-level, contextual regression for $\mathrm{D}$ and $\mathrm{S}$ the specification is $\mathrm{y}=b_{0}+b_{1}($ race $)+b_{2}(\operatorname{lnp}$ $\mathrm{op})+b_{3}(\mathrm{rpb})+b_{4}($ race $\cdot$ lnpop $)+b_{5}($ race $\cdot \mathrm{rpb})+b_{6}($ income $)+b_{7}($ income $\cdot$ race $)$. Implied city-level effects are $b_{1}, b_{4}$, and $b_{5}$. To make intercepts substantively meaningful, lnpop and rbp are centered on values near the low end of the observed sample distribution; specificall, lnpop is centered on 12.0 and $\mathrm{rbp}$ is centered on 0.1

White-Black differences in residential contact with Whites (coded to reflect how contact determines values of $\mathrm{D}$ and $\mathrm{S}$ ) decrease only modestly when White-Black differences in socioeconomic characteristics are taken into account at the individuallevel; that is, by drawing on micro-level data to standardize the White-Black comparison to take account of the impact of group differences in income separately in each city based on the city-specific race-income-residence relationship at the individual level for that city.

The third column of Table 10.3 presents city-level regressions that replicate another finding reported in Fossett (1988). The dependent variables for these analyses, D* and S*, are values of D and S that have been "standardized" so they represent differences in residential outcomes between Whites and Blacks with identical 
Table 10.3 Analyses illustrating how city-level analyses of segregation can yield misleading results when aggregate measures are used to control for group differences on non-racial characteristics

City-level regressions for White-Black segregation - Observed Dissimilarity (D) and Standardized Dissimilarity (D*)

\begin{tabular}{lccc}
\hline & $\mathrm{D}$ & $\mathrm{D}$ & \multicolumn{1}{c}{$\mathrm{D}^{*}$} \\
\hline Unstandardized regression coefficients & & & \\
$\quad$ City size (lnpop) & $3.90^{\mathrm{a}}$ & $4.23^{\mathrm{a}}$ & $4.43^{\mathrm{a}}$ \\
$\quad$ Relative minority size (rpb) & 4.79 & $-10.36^{\mathrm{c}}$ & -6.79 \\
$\quad$ Ratio of mean incomes (B/W) & - & $-40.29^{\mathrm{a}}$ & $-29.43^{\mathrm{a}}$ \\
Standardized regression coefficients & & & \\
$\quad$ City size (lnpop) & $0.399^{\mathrm{a}}$ & $0.423^{\mathrm{a}}$ & $0.427^{\mathrm{a}}$ \\
Relative minority size (rpb) & 0.063 & $-0.136^{\mathrm{c}}$ & -0.086 \\
$\quad$ Ratio of mean incomes (B/W) & - & $-0.538^{\mathrm{a}}$ & $-0.379^{\mathrm{a}}$ \\
Sample N & 201 & 201 & 201 \\
\hline
\end{tabular}

City-level regressions for White-Black segregation - Observed Separation Index (S) and Standardized Separation Index $\left(\mathrm{S}^{*}\right)$

\begin{tabular}{lrrr}
\hline & $\mathrm{S}$ & $\mathrm{S}$ & \multicolumn{1}{c}{$\mathrm{S}^{*}$} \\
\hline Unstandardized regression coefficients & & & \\
$\quad$ City size (lnpop) & $5.83^{\mathrm{a}}$ & $6.32^{\mathrm{a}}$ & $6.24^{\mathrm{a}}$ \\
Relative minority size (rpb) & $70.51^{\mathrm{a}}$ & $48.04^{\mathrm{a}}$ & $52.01^{\mathrm{a}}$ \\
$\quad$ Ratio of mean incomes (B/W) & - & $-59.75^{\mathrm{a}}$ & $-45.37^{\mathrm{a}}$ \\
Standardized regression coefficients & & & \\
$\quad$ City size (lnpop) & $0.360^{\mathrm{a}}$ & $0.391^{\mathrm{a}}$ & $0.406^{\mathrm{a}}$ \\
Relative minority size (rpb) & $0.571^{\mathrm{a}}$ & $0.389^{\mathrm{a}}$ & $0.444^{\mathrm{a}}$ \\
Ratio of mean incomes (B/W) & - & $-0.494^{\mathrm{a}}$ & $-0.396^{\mathrm{a}}$ \\
Sample N & 201 & 201 & 201 \\
\hline
\end{tabular}

Source: Summary File 3, Census 2000

${ }^{\mathrm{a}} \mathrm{p}<0.001$

${ }^{\mathrm{b}} \mathrm{p}<0.01$

${ }^{c} \mathrm{p}<0.05$

income distributions. Drawing on techniques discussed earlier in Chapter 9, the standardization is accomplished by calculating $\mathrm{D}^{*}$ and $\mathrm{S} *$ from predicted means on segregation-relevant residential outcomes for Whites and Blacks with identical levels of income based on city- and group-specific individual-level regressions of residential outcomes on income. Since $\mathrm{D}^{*}$ and $\mathrm{S}^{*}$ reflect White-Black differences in residential outcomes for families that have identical levels of income, city variation in $\mathrm{D}^{*}$ and $\mathrm{S}^{*}$ cannot be attributed to city variation in group income differences. Nevertheless, the city-level measure of racial income inequality continues to have very strong and statistically significant effects on $\mathrm{D}^{*}$ and $\mathrm{S}^{*}$ in the city-level regressions.

There is a ready explanation for this result. It is that the aggregate-level association of segregation and socioeconomic differences reflects much more than the narrow impact of racial income differences on racial differences in residential outcomes. 
Drawing on arguments set forth in more detail in Fossett (1988) I suggest that the strong effect of racial income inequality in this equation is misleading and primarily reflects a spurious association. My interpretation is guided by the simple hypothesis that aggregate racial inequality in all important areas of socioeconomic attainment are likely to co-vary because they all are likely to share a common cause; they vary together based on the general salience of race and minority disadvantage in socioeconomic attainment dynamics in the community stratification system. To the extent that this is so, racial segregation and racial income inequality will be correlated at the aggregate level even when White-Black income differences play a minor role in shaping White-Black residential segregation. The regression results reported in column 3 are consistent with this hypothesis. This in turn indicates that the strong effects of racial income inequality in the regression results reported in column 2 are misleading.

The interpretation I offer regarding the effect of income inequality in aggregatelevel regressions predicting segregation is at odds with the usual interpretation offered aggregate-levels studies of segregation. But it is consistent with findings from micro-level studies of the role of group income differences in shaping WhiteBlack segregation. Studies that draw on micro-data that disaggregate residential outcomes by income and race simultaneously consistently report that White-Black income differences are not a major factor contributing to segregation between the groups. For example, analyses performed for individual cities typically report that index scores for White-Black segregation are as high when computed for households that are matched on income (or other socioeconomic characteristics) as when computed for the full populations (Farley 1977; Denton and Massey 1988; Massey and Fischer 1999). I observe the same pattern in the city-specific income standardization exercises that generated the $\mathrm{D}^{*}$ and $\mathrm{S}^{*}$ index scores used in the aggregate analyses reported here.

In sum, then, there is little available evidence from analysis of detailed microdata for individual cities to indicate that White-Black income differences play a major role in producing residential separation of Whites and Blacks. The reason is simple; Whites at all income levels tend to live apart from Blacks at all income levels. Findings of this sort based on analysis of disaggregated micro-data should be seen as more compelling than findings from aggregate correlations of racial income differences and racial segregation. Researchers seeking to properly assess the impact of group differences in non-racial characteristics (e.g., income) on segregation must directly examine how residential attainments vary with those characteristics separately by race in each community using disaggregated micro-level data. The framework for studying segregation set forth here allows researchers to investigate these questions in a methodologically sound way. It allows them to assess the role of group differences on non-racial characteristics such as income using individual-level contextual models of attainment. The alternative approach of including measures of socioeconomic inequality in city-level analyses of segregation is flawed and prone to yielding misleading results as seen in the example here. It should be abandoned. 


\section{References}

Denton, N., \& Massey, D. S. (1988). Residential segregation of Blacks, Hispanics, and Asians by socioeconomic status and generation. Social Science Quarterly, 69, 797-817.

Farley, R. (1977). Residential segregation in urbanized areas of the United States in 1970: An analysis of social class and racial differences. Demography, 14, 497-518.

Farley, R., \& Frey, W. H. (1994). Changes in the segregation of Whites from Blacks during the 1980s: Small steps toward a more integrated society. American Sociological Review, 59, 23-45.

Fossett, M. (1988). Community-level analyses of racial socioeconomic inequality: A cautionary note. Sociological Methods and Research, 16, 454-491.

Marshall, H., \& Jiobu, R. (1975). Residential segregation in United States cities: A causal analysis Social Forces, 53, 449-460.

Massey, D. S., \& Denton, N. A. (1987). Trends in the residential segregation of Blacks, Hispanics, and Asians. American Sociological Review, 52, 802-825.

Massey, D. S., \& Fischer, M. J. (1999). Does rising income bring integration? New results for Blacks, Hispanics, and Asians in 1990. Social Science Research, 28, 316-326.

Roof, W. C., Van Valey, T. L., \& Spain, D. (1976). Residential segregation in southern cities: 1970. Social Forces, 55, 59-71.

Open Access This chapter is licensed under the terms of the Creative Commons AttributionNonCommercial 2.5 International License (http://creativecommons.org/licenses/by-nc/2.5/), which permits any noncommercial use, sharing, adaptation, distribution and reproduction in any medium or format, as long as you give appropriate credit to the original author(s) and the source, provide a link to the Creative Commons license and indicate if changes were made.

The images or other third party material in this chapter are included in the chapter's Creative Commons license, unless indicated otherwise in a credit line to the material. If material is not included in the chapter's Creative Commons license and your intended use is not permitted by statutory regulation or exceeds the permitted use, you will need to obtain permission directly from the copyright holder.

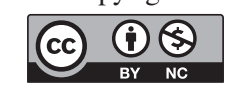

